Tetrahedron Letters

journal homepage: www.elsevier.com

\title{
Trapping Hemiacetals with Phosphono Substituted Palladium $\pi$-Allyl Complexes for the Synthesis of Substituted Cyclic Ethers
}

\author{
Nongnuch Sutivisedsak, Surendra Dawadi and Christopher D. Spilling* \\ Department of Chemistry and Biochemistry, University of Missouri - St. Louis, One University Boulevard, St. Louis, Missouri, 63121, USA
}

\section{ARTICLE INFO}

Article history:

Received

Received in revised form

Accepted

Available online

Keywords:

Vinyl phosphonates

Allyl phosphonates

Acetal

Cyclization

Palladium $\pi$-allyl

Catalysis

\section{ABSTRACT}

Oxidation of hydroxy substituted phosphono allylic carbonates gave the aldehyde substituted phosphonates in good yield. Stereospecific palladium (0)-catalyzed cyclization in the presence of methanol or water gave acetal tetrahydrofuran and tetrahydropyran vinyl phosphonate products derived from hemiacetal trapping. The tetrahydrofuran acetals undergo Lewis acid catalyzed addition of nucleophiles to give diastereoisomeric mixtures of substituted tetrahydrofurans.

2009 Elsevier Ltd. All rights reserved.

\section{Introduction}

We recently described the palladium-catalyzed intramolecular addition of hydroxyalkyl phosphono allylic carbonates to give tetrahydrofuran (THF) and tetrahydropyran (THP) vinyl phosphonates. ${ }^{1}$ Tetrahydrofurans and tetrahydropyrans are structures frequently found in several important classes of biologically active natural products, such as polyether antibiotics, acetogenins, and C-glycosides. Due to the wide distribution of tetrahydrofurans and tetrahydropyrans in nature, many reactions have been developed for their synthesis. ${ }^{2}$ A popular approach is the addition of carbon nucleophiles to oxacarbenium ions prepared from cyclic acetal containing THF and THP precursors. ${ }^{2 a-c}$ The stereochemistry of the addition of nucleophiles to cyclic oxacarbenium ions has been thoroughly analyzed. $^{3}$

We postulated (Scheme 1) that a mixture of aldehyde $\mathbf{1}$ and an alcohol would result in an equilibrium concentration of hemiacetal 2, which could be trapped by an electrophilic palladium $\pi$-allyl intermediate 3 to form a cyclic acetal 4 . Alternatively, the aldehydic palladium $\pi$-allyl $\mathbf{5}$ could form first and then cyclize, either directly to give a carbenium ion $\mathbf{6}$ (which is then trapped by alcohol) or via the hemiacetal 3. However, if the hemiacetal (or aldehyde) lack sufficient nucleophilicity or concentration, the palladium $\pi$-allyl intermediate $\mathbf{3}$ will likely eliminate producing diene 7 . If successfully formed, the resulting cyclic hemiacetal $\mathbf{4}$ could then be utilized for the synthesis of cyclic ethers via nucleophilic addition to an oxacarbenium ion. ${ }^{2 a-}$ $\mathrm{c}, 3$

\footnotetext{
${ }^{*}$ Corresponding author. Tel.: 314-516-5437; fax 314-516-5432.

E-mail address: cspill@umsl.edu
}

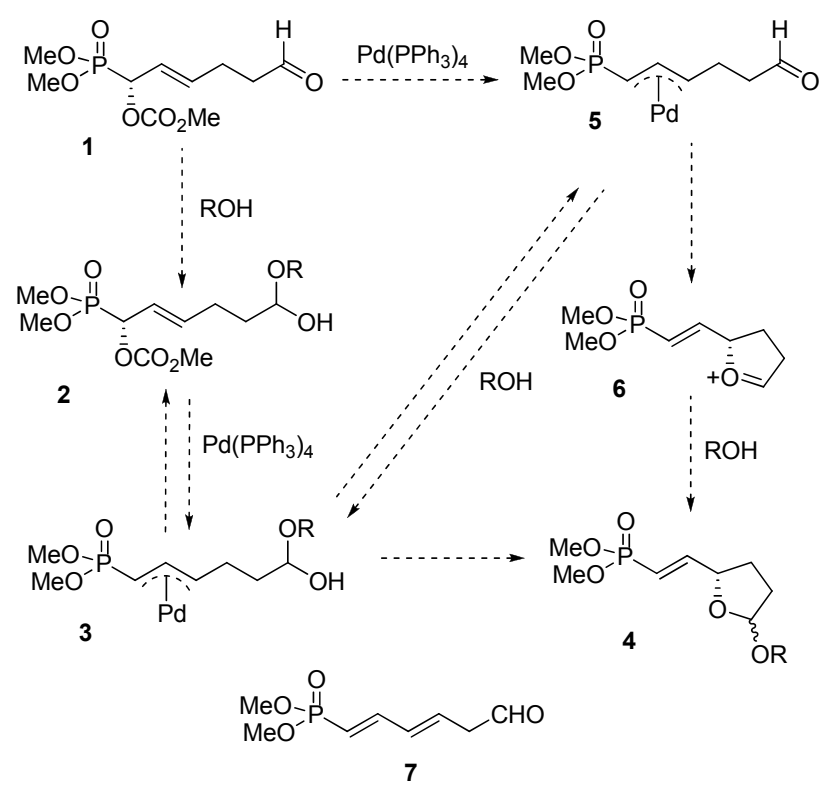

Scheme 1. Proposed intramolecular trapping of a hemiacetal with a palladium $\pi$-allyl complex.

In support of this hypothesis, we reported an adaptation of Leighton's mercuric hemiacetal trapping ${ }^{4}$ using allylic hydroxy phosphonates as the substrate. ${ }^{5} \mathrm{~A}{ }^{31} \mathrm{P}$ NMR spectrum of a solution of the hydroxy phosphonate in a mixture of propanal and 
$\mathrm{CDCl}_{3}$ clearly showed the presence of equilibrium concentrations of hemiacetal. Further support is found in the report that allenyl aldehydes undergo palladium (II) catalyzed cyclization in alcohol solution under an atmosphere of $\mathrm{CO}$ to give THF-substituted unsaturated esters. ${ }^{6}$ In addition, alkylhemiacetals (aldehydes in alcohol solution) with allylic OTHP leaving groups have been shown to react via palladium(II) intermediates to give cyclic acetals. ${ }^{7}$ Thus, it is apparent that a hemiacetal should be both sufficiently nucleophilic and present in high enough concentration, to react with a palladium $\pi$-allyl intermediate.

\section{Results and Discussion}

The required aldehydes $\mathbf{1 a}$ and $\mathbf{1 b}$ were prepared from the previously reported hydroxy substituted phosphonates $\mathbf{8 a}$ and $\mathbf{8 b}{ }^{1}$ Reaction of phosphonates $\mathbf{8 a}$ and $\mathbf{8 b}$ with pyridinium chlorochromate (PCC) in $\mathrm{CH}_{2} \mathrm{Cl}_{2}$ gave the aldehydes $\mathbf{1 a}$ and $\mathbf{1 b}$ in $88 \%$ and $72 \%$, respectively (Scheme 2). Gratifyingly, treatment of aldehyde 1a with $\mathrm{Pd}\left(\mathrm{PPh}_{3}\right)_{4}$ and Hunig's base in a 1:1 mixture of THF and $\mathrm{MeOH}$ gave a 3:1 diastereoisomeric mixture of THF-methoxy acetals $4 \mathbf{a}$ in $81 \%$ yield. The homolog 1b reacted under similar conditions to give the THP-methoxy acetals $4 \mathbf{b}$ in $66 \%$ yield. The methoxy acetal $4 \mathbf{a}$ was hydrolyzed using Dowex 50 in aqueous THF to give a cyclic hemiacetal $4 \mathbf{c}$ $(82 \%)$, which reacted with acetic anhydride and DMAP/pyridine in $\mathrm{CH}_{2} \mathrm{Cl}_{2}$ to give the corresponding acetoxy acetal $9 \mathrm{a}$ in $91 \%$ yield. In a more direct route to the acetoxy acetal 9a, the aldehyde 1a was reacted with $\mathrm{Pd}\left(\mathrm{PPh}_{3}\right)_{4}$ in aqueous THF to give the hemiacetal $4 \mathbf{c}$ directly. The solvents were removed and the crude hemiacetal $4 \mathbf{c}$ was acetylated to give the acetoxy acetal 9a (68\% for 2 steps). Again, the homologous aldehyde 1b was treated under similar conditions to yield the THP-acetoxy acetal in $63 \%$ (for 2 steps). Finally, the carboxylic acid 10a was reacted with $\mathrm{Pd}\left(\mathrm{PPh}_{3}\right)_{4}$ and Hunig's base in THF to give corresponding lactone 11a. Surprisingly, the homologous acid 10b failed to cyclize and only the formation of a mixture of diene products $\mathbf{7 b}$ was observed.

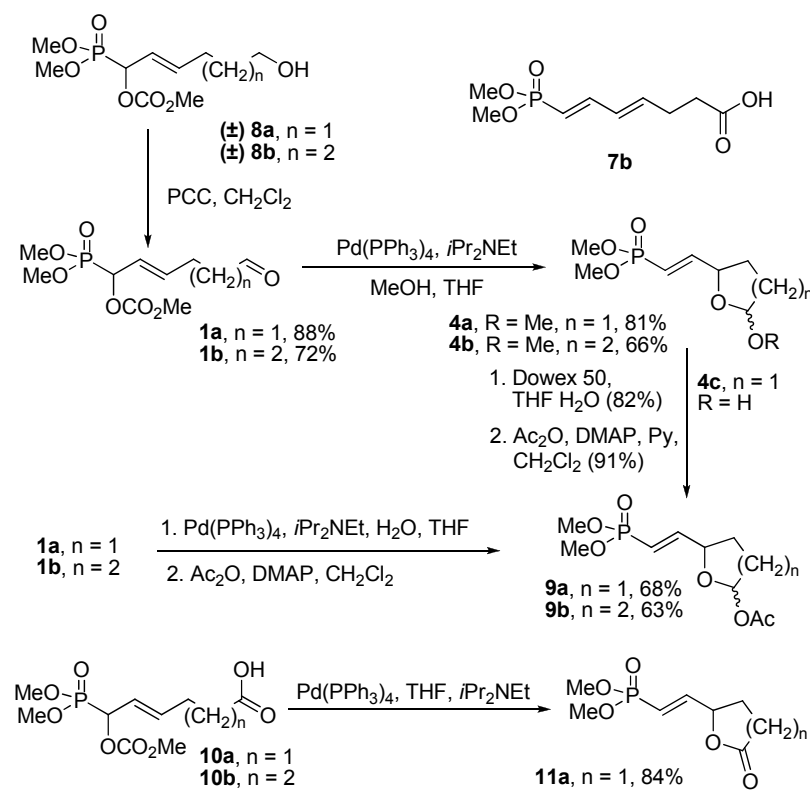

Scheme 2. Palladium-catalyzed cyclization of aldehyde-derived hemiacetals and carboxylic acids.

Reductive removal of the acetal stereocenter allowed an examination of the extent of chirality transfer in the cyclization reaction. Nonracemic hydroxy phosphonate $(\boldsymbol{R}) \mathbf{8 a}$ was oxidized to the aldehyde $(\boldsymbol{R}) \mathbf{1} \mathbf{a}$, which was cyclized using $\mathrm{Pd}\left(\mathrm{PPh}_{3}\right)_{4}$ and Hunig's base in aqueous THF at $40^{\circ} \mathrm{C}$ to give the corresponding hemiacetal $\mathbf{4 c}$, which was acetylated to give the acetoxy acetal 9a. As expected, HPLC on chiral stationary phase was complicated by the mixture of diastereoisomers which resulted in overlapping peaks. The acetoxy acetal 9a was reduced (Scheme 3) with $\mathrm{Et}_{3} \mathrm{SiH}$ and TMSOTf in $\mathrm{CH}_{3} \mathrm{CN}$ to give the previously reported THF-vinyl phosphonate 12. ${ }^{1}$ HPLC analysis showed complete chirality transfer in the transformation of $\mathbf{8}$ to $\mathbf{1 2}$.

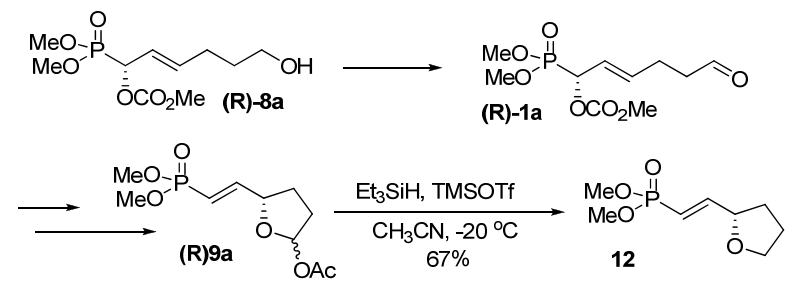

Scheme 3. Reduction of the acetoxy acetal.

We suspected that a chiral center next to the aldehyde would be vulnerable to racemization under the reaction conditions. To examine this potential problem, a nonracemic aldehyde was prepared bearing a $\alpha$-methyl substituent (Scheme 4). The acyl oxazolidinone 13, prepared following a literature procedure, ${ }^{8}$ was coupled with nonracemic phosphono allylic carbonate 14 (95\% e.e.) using the Grubbs second generation catalyst and copper(I) iodide as co-catalyst to give phosphonate 15. ${ }^{1,9}$ The oxazolidinone auxiliary was reductively cleaved using lithium borohydride ${ }^{10}$ to yield the alcohol $\mathbf{1 6}$, which was oxidized using Dess Martin periodinane ${ }^{11}$ to the corresponding aldehyde 17. The aldehyde was cyclized with $\mathrm{Pd}\left(\mathrm{PPh}_{3}\right)_{4}$ in aqueous $\mathrm{THF}$ at $40^{\circ} \mathrm{C}$ to give the corresponding hemiacetal, which was acetylated to give the acetoxy acetal 18. Again, HPLC on chiral stationary phase was complicated by overlapping peaks. The acetoxy acetal 9a was reduced with TMSOTf and $\mathrm{Et}_{3} \mathrm{SiH}$ in $\mathrm{CH}_{3} \mathrm{CN}$ to give THFvinyl phosphonate $\mathbf{1 9}$ as 3:1 mixture of diastereoisomers. In addition, the acetoxy acetal was hydrolyzed and the hemiacetal oxidized to give the lactone $\mathbf{2 0}$ as $2: 1$ mixture of diastereoisomers. Clearly, significant racemization occurs under the reaction conditions even in the absence of an amine base.
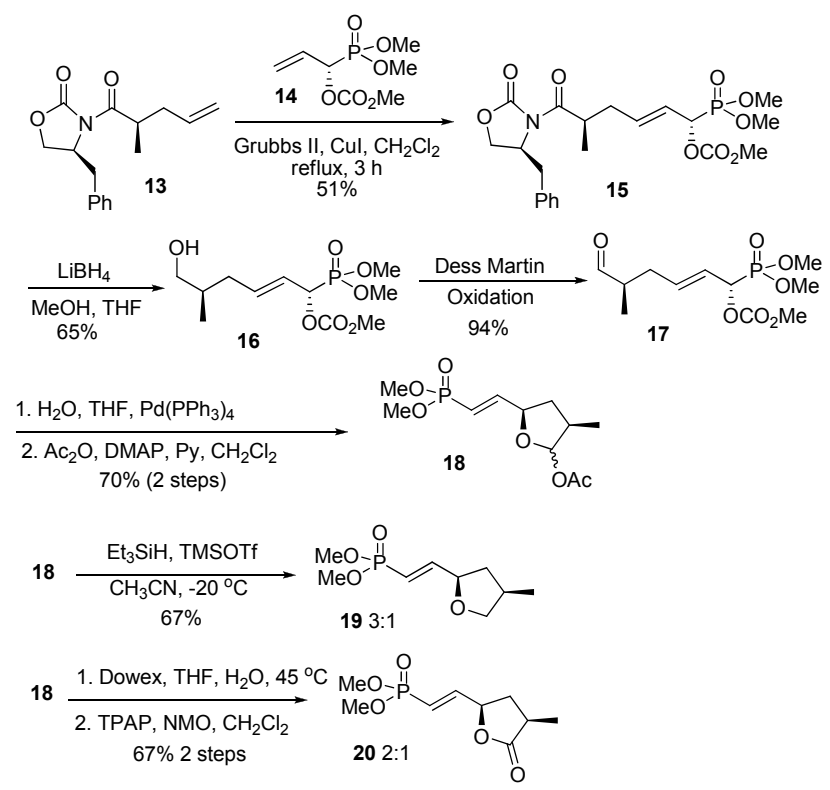

Scheme 4. Palladium-catalyzed cyclization of chiral hemiacetal. 
To further examine the substrate scope, ketone $\mathbf{2 1}$ was prepared using a cross metathesis reaction of phosphono allylic carbonate 14 with hex-5-en-2-one (Scheme 5). Treatment of ketone 21 with $\mathrm{Pd}\left(\mathrm{PPh}_{3}\right)_{4}$ and Hunig's base in a 1:1 mixture of THF and $\mathrm{MeOH}$ gave a separable mixture of THF-methoxy acetals 22, methoxy vinyl phosphonate $\mathbf{2 3}$ and hydroxy vinyl phosphonate $\mathbf{2 4}$. The hydroxy vinyl phosphonate $\mathbf{2 4}$ is formed by hydrolysis of the THF-methoxy acetals $\mathbf{2 2}$ on silica gel. Formation of the methoxy vinyl phosphonate is an indication that intermolecular addition of solvent is competitive with the intramolecular addition of the hemiacetal. This could a consequence of the lower equilibrium concentration of the hemiacetal or the increased steric size of the nucleophile.
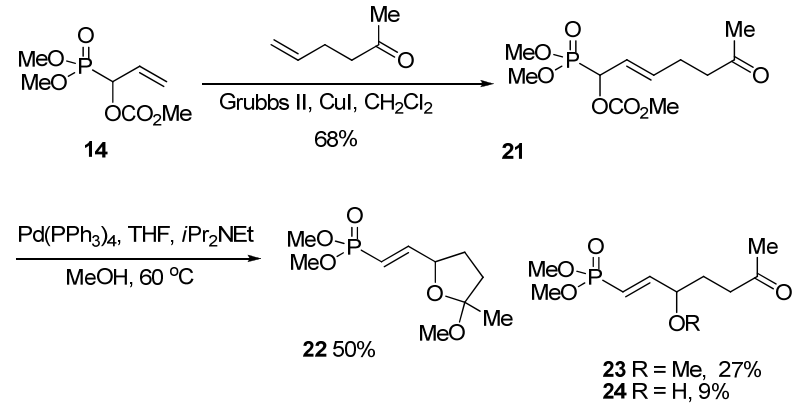

Scheme 5. Palladium-catalyzed cyclization of ketone-derived hemiacetals.

Hemiacetals formed by dissolving alcohols in aldehyde solvents should also be substrates for cyclization. ${ }^{4,5}$ Thus, treatment of a propanal solution of the hydroxy substituted phosphono allylic carbonate 8c with $\mathrm{Pd}\left(\mathrm{PPh}_{3}\right)_{4}$ gave the cyclic acetal 25 in $68 \%$ yield (Scheme 6). However, reaction of the same alcohol 8c with chloral hydrate in THF followed by treatment with $\mathrm{Pd}\left(\mathrm{PPh}_{3}\right)_{4}$ and Hunig's base resulted in the formation of formate 26, presumably by elimination of chloroform from intermediate 27 , which was observed by $31 \mathrm{P}$ NMR spectroscopy.

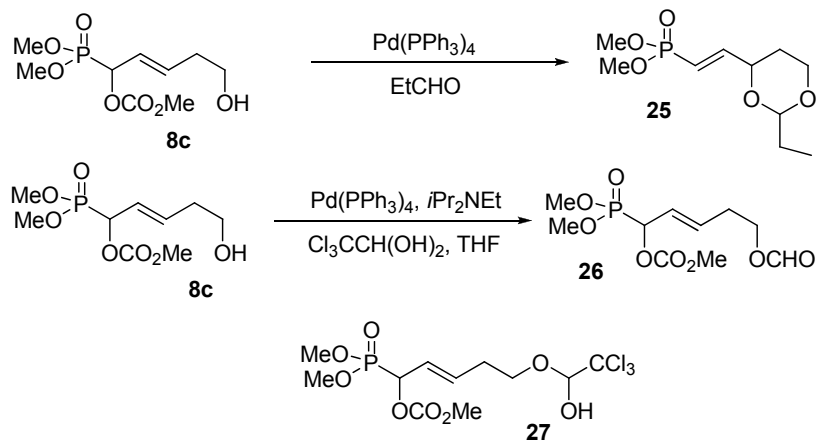

Scheme 6. Palladium-catalyzed cyclization of alcohol-derived hemiacetals.

With cyclic acetals (4a and 9a) in hand, the Lewis acid catalyzed additions of some representative nucleophiles were examined (Scheme 7). Reaction of the THF-methoxy acetal 4a with allyl trimethylsilane and trimethylsilyl triflate (TMSOTf) ${ }^{12}$ gave the allyl substituted THF 28a as a 2.3:1 mixture of diastereoisomers in $95 \%$ yield. The nucleoside analog $\mathbf{2 8 b}$ was prepared in $61 \%$ yield as 2.9:1 mixture of diastereoisomers by reaction with 2,4-bis-(trimethylsilyloxy)pyrimidine ${ }^{13}$ and TMSOTf in $\mathrm{CH}_{3} \mathrm{CN}$. Surprisingly, attempted addition of the silyl ketene acetal $\left[\mathrm{CH}_{2}=\mathrm{C}(\mathrm{OTBS})(\mathrm{OEt})\right]^{14}$ to the methoxy acetal $4 \mathbf{a}$ or acetoxy acetal 9a failed and only the THF-vinyl phosphonate 12, resulting from reduction of the oxacarbenium ion, was observed. However, reaction of the acetoxy acetal 9a with the zinc enolate ${ }^{15}$ and $\mathrm{TiCl}_{4}$ in $\mathrm{CH}_{2} \mathrm{Cl}_{2}$ gave the $\mathrm{C}$-acetate $28 \mathrm{c}$ in 61 $\%$ yield as 1.2:1 mixture of diastereoisomers.

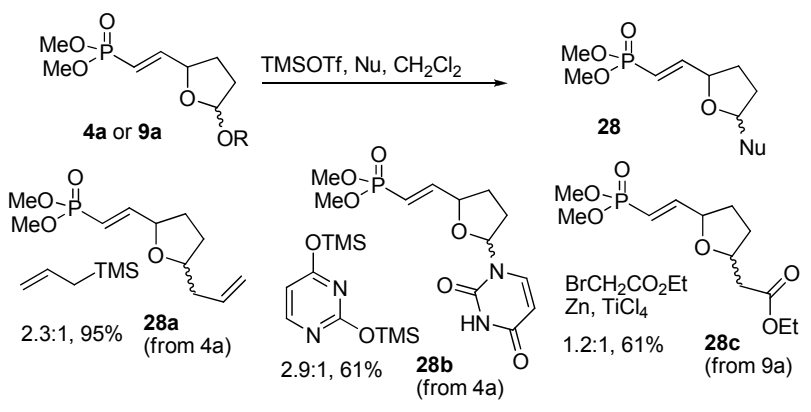

Scheme 7. Lewis acid catalyzed addition of nucleophiles.

In summary, we have shown the hemiacetals can be trapped by intramolecular reaction with palladium $\pi$-allyls to give cyclic acetals. The resulting cyclic acetals (methoxy $4 \mathbf{a}$ or acetoxy 9a) undergo Lewis acid catalyzed addition of nucleophiles to give substituted tetrahydrofuran vinyl phosphonates.

\section{Acknowledgments}

The project described was supported in part by grant number R01-GM076192 from the National Institute of General Medicine. We thank National Science Foundation for grants to purchase the NMR spectrometer (CHE-9974801), and the mass spectrometer (CHE-9708640). We thank Mr. Joe Kramer and Prof. R.E.K. Winter of the Department of Chemistry and Biochemistry, UMSL for mass spectra.

\section{Supplementary Material}

Supplementary data (experimental procedures and ${ }^{31} \mathrm{P},{ }^{1} \mathrm{H}$ and ${ }^{13} \mathrm{C}$ NMR spectra) associated with this article can be found online. This material is available free of charge via the Internet.

\section{References and notes}

1. a) He, A.; Sutivisedsak, N.; Spilling, C. D. Org. Lett. 2009, 11, 3124-3127. (b) Roy, S.; Spilling, C. D. Org. Lett. 2010, 12, 53265329. c) Roy, S.; Spilling, C. D. Org. Lett. 2012, 14, 2230-2233.

2. For reviews see (a) Boivin, T. L. B. Tetrahedron 1987, 43, 33093362. (b) Harmange, J.-C.; Figadére, B. Tetrahedron: Asymmetry 1993, 4, 1711-1754. (c) Koert, U. Synthesis 1995, 115-132. d) Hyland, C. Tetrahedron 2005, 61, 3457-3471. (e) Clarke, P. A.; Santos, S. Eur. J. Org. Chem. 2006, 2045-2053. (f) Wolfe, J. P.; Hay, M. B. Tetrahedron 2007, 63, 271-290. g) Muzart, J. J. Mol. Catal. A 2010, 319, 1-29.

3. a) Bear, T. J.; Shaw, J. T.; Woerpel, K. A. J. Org. Chem. 2002, 67, 2056-2064. b) Ayala, L.; Lucero, C. G.; Romero, J. A. C.; Tabacco, S. A.; Woerpel, K. A. J. Am. Chem. Soc. 2003, 125, 15521-15528. c) Smith, D. M.; Tran, M. B.; Woerpel, K. A. J. Am. Chem. Soc. 2003, 125, 14149-14152. d) Smith, D. M.; Woerpel, K. A. Org. Lett. 2004, 6, 2063-2066. e) Chamberland, S.; Ziller, J. W.; Woerpel, K. A. J. Am Chem. Soc. 2005, 127, 5322-5323. f) Larsen, C. H.; Ridgway, B. H.; Shaw, J. T.; Smith, D. M. Woerpel, K. A. J. Am. Chem. Soc. 2005, 127, 10879-10884. g) Shenoy, S. R.; Smith, D. M.; Woerpel, K. A. J. Am Chem. Soc. 2006, 128, 8671-8677

4. a) Sarraf, S. T.; Leighton, J. L. Org. Lett. 2000, 2, 403. b) Dreher, S. D.; Hornberger, K. R.; Sarraf, S. T.; Leighton, J. L. Org. Lett. 2000, 2, 3197-3199

5. Thanavaro, A.; Spilling, C. D. Phosphorus, Sulfur and Silicon 2002, 177, 1583-1586. 


\section{Tetrahedron}

6. a) Walkup, R. D.; Mosher, M. D. Tetrahedron 1993, 49, 92859294. b) Walkup, R. D.; Mosher, M. D. Tetrahedron Lett. 1994, $35,8545-8548$.

7. a) Awasaguchi, K.-I.; Miyazawa, M.; Uoyo, I.; Koichi, I.; Nakamura, K.; Yokoyama, H.; Harai, Y. Heterocycles 2010, 81 2105-2121. b) Miyazawa, M.; Awasaguchi, K.-I.; Uoyo, I.; Yokoyama, H.; Hirai, Y. Heterocycles 2010, 81, 1891-1902.

8. Schinzer, D.; Bauer, A.; Schieber, J. Chem. Eur. J. 1999, 5, 24922500.

9. Spilling, C. D.; He, A.; Yan, B.; Thanavaro, A. J. Org. Chem. 2004, 69, 8643-8651.

10. Evans, D. A.; Allison, D. B.; Yang, M. G.; Masse, C. E. J. Am. Chem. Soc. 2001, 123, 10840-10852.
11. a) Mitchell, I. S.; Pattenden, G.; Stonehouse, J. Org. Biomol. Chem. 2005, 3, 4412-4431. b) Arai, N.; Chikaraishi, N.; Omura, S.; Kuwajima, I. Org. Lett. 2004, 6, 2845-2848.

12. Gadikota, R. R.; Callam, C. S.; Lowary, T. L. J. Org. Chem. 2001, 66, 9046-9051.

13. Roy, A.; Sahabuddin, S.; Achari, B.; Mandal, S. B. Tetrahedron 2005, 61, 365-371.

14. Denmark, S. E.; Beutner, G. L.; Wynn, T.; Eastgate, M. D. J. Am. Chem. Soc. 2005, 127, 3774-3789.

15. Zinc Hayashi, M.; Sugiyama, M.; Toba, T.; Oguni, N. Chem. Commun. 1990, 767-768. Chattopadhyay, A.; Salaskar, A. Synthesis 2000, 561-564. 


\section{Graphical Abstract}

To create your abstract, type over the instructions in the template box below.

Fonts or abstract dimensions should not be changed or altered.

Trapping Hemiacetals with Phosphono Substituted Palladium $\pi$-Allyl Complexes for the Synthesis of Substituted Cyclic Ethers

Nongnuch Sutivisedsak, Surendra Dawadi and Christopher D. Spilling*

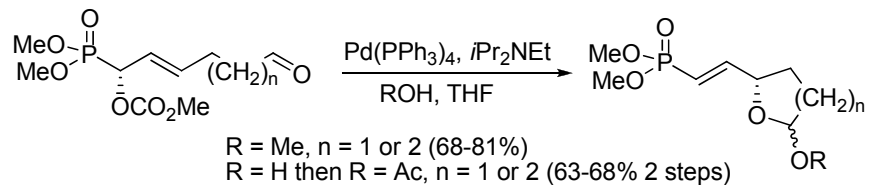

$\mathrm{R}=\mathrm{H}$ then $\mathrm{R}=\mathrm{Ac}, \mathrm{n}=1$ or $2(63-68 \% 2$ steps $)$

\section{Leave this area blank for abstract info.}
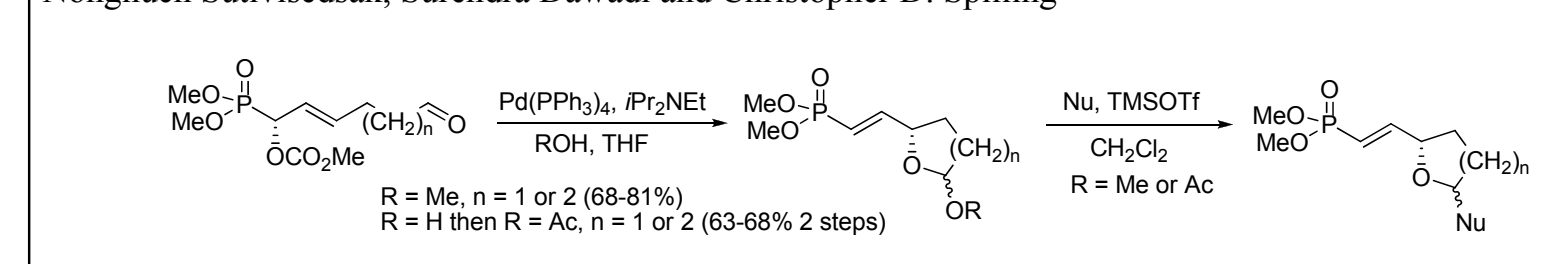